\title{
Teaching Intervention Strategies that Enhance Learning in Higher Education
}

\author{
Robert P Machera \\ Department of Accounting and Finance, Faculty of Business and Accounting, Botho University, Botswana
}

Copyright $(\mathrm{C} 2017$ by authors, all rights reserved. Authors agree that this article remains permanently open access under the terms of the Creative Commons Attribution License 4.0 International License

\begin{abstract}
[8] argues that self-assessment and peer-assessment are becoming popular and valuable to students and lecturers as this approach prepares the students to be accountable and responsible. There are benefits that accrue to this intervention if it is properly administered and some of the benefits include self-directing, cooperation and collaboration among the learners. [6] agrees that self-assessment and peer-assessment, assist students to be competitive in the job market, as they are able to work with less supervision in their future employment opportunities. The aim of this paper was to investigate whether higher education should implement self-assessment and peer-assessment as part of enhancing students' opportunities for access to employment. This study used a purposive sampling method and a sample size (n) of 90 participants. The data for this study was collected from three classes enrolled in the Association of Accounting Technician (AAT) Programme at Botho University in Botswana. At Botho University each class consists of 30 students and therefore three classes constitute a sample size of 90 participants. The participants were given questionnaires in order to response on the effect of interventions that were administered by the researcher during class lessons. The main findings of this study reflected that there were benefits from proper and well-coordinated self-assessment and peer-assessment. These benefits accrue from both lecturers, students, institutions of higher learning and potential employers. The results have shown that they would be improvements in the administration of self-assessment and peer-assessment. Ultimately self-assessment and peer-assessment provide effective and prompt feedback, which invariably impacted positively to the quality of the teaching delivery. The significance of self-assessment and peer-assessment to all educational stakeholders has prompted the author to conduct this study. Furthermore, based on the results from the participants it was recommended that self-assessment and peer-assessment enhance learning in higher education hence the need to implement these teaching intervention strategies.
\end{abstract}

Keywords Intervention Strategies, Self-assessment, Peer-assessment, Feedback, Enhance Learning, Self-directing and Collaboration

\section{Introduction}

Higher Education is faced with challenges of limited student self-learning and self-directing. The researcher experimented on semester three students at Botho University who were taking Basic Costing as their module during the July 2012 to December 2012 semester. The researcher compared the students' grades, tutor's grades and the student's own grades as a test to prove whether it was inevitable to introduce self-and peer-assessment in the classroom. Self-assessment is one of the effective approaches where students assess their own test, assignments or projects.

This approach was proved to be effective by "Paul Black in his Paper" (1998) on "Assessment and Classroom Learning, Assessment in Education." Black's paper yielded positive results and this motivated the researcher of this paper to carry out an intervention on ninety students who were in the AAT batches for semester three at Botho University. The results for the selected group was positive hence this same approach may be used to the rest of the AAT students or future research should be conducted by other researchers in this field. The adult educator found out that the students were motivated in assessing their work as well as willing to learn.

This phenomenon of self-and peer-assessment also helps the students in terms of acquisition of new skills that will assist them when they are engaged on full time employment. This approach demonstrated that the students will a learn variety of tasks and hence they become responsible and accountable at an early stage. According to [7] acquiring a new skill at an early stage helps a candidate to be competitive on the job market hence it was inevitable for this researcher to conduct this study. Self-and peer-assessment assist students as part of professional development and when they become accountants it would be easy for them to move from the novice to an expert, since they would have been oriented at an early stage. Furthermore there are many benefits that derive from the self-and peer-assessment which have been explained in the subsequent sections.

\subsection{Problem Statement}

In the AAT department at Botho University faculty 
members are given three classes to teach and a class constitute of thirty students. It is imperative for these students to write at least five mock examinations before they write the final assessment. These mock assessments act as formative feedback hence the need for prompt results. It is from this background that the author of this study was motivated to conduct this research. The self-and peer-assessment fosters debate among educators on the credibility of grades that are granted based on this concept unless if it is carried out for formative assessment only. The issue is that how much trust does the public give to a qualification obtained through self-and peer-assessment. Most educators agreed that it is imperative to encourage self-and peer -assessment as formative feedback rather than summative (final assessment), in order to get confidence from the society.

Furthermore, self-assessment and peer-assessment improves the relationships between the teacher and student. This study focuses on the restoration of the relationship between the teacher and the student. [10] postulate that self-assessment was important from a student's perspective as it enhances self-directed professionals to fit easily in the real world. Therefore, this study will address and prove that effective self-assessment and peer - assessment improves the teacher and student's relationship. Therefore the researcher was motivated to conduct this study and to draw some conclusions about how this approach may assist the students, teachers, educational institutions and the employers at large. The next section of this paper focuses on the purpose of the study.

\subsection{Purpose of the Study}

The main purpose of this paper is to identify approaches that prepare the students for self-learning and self-directing in the AAT department within Botho University.

\subsection{Objectives of the Study}

The first objective is to find out whether self-assessment and peer-assessment improves students' performance.

The second objective of this study is to find out whether there are benefits that accrue from well administered self-and peer-assessment.

The third objective is to see whether self-assessment and peer-assessment may be implemented in higher education.

The next section focuses on the research questions that will be answered in this study.

\subsection{Research Questions}

The research questions for this study are as follows:
- What are the students' reactions towards their performance after implementing self-assessment and peer-assessment?

- What are the benefits that accrue from well administered self-assessment and peer-assessment?

- What are the recommendations based on the participants' feelings towards implementation of self-assessment and peer-assessment in higher education?

The next section focuses on the scope of the study.

\subsection{Scope of the Study}

This section focuses on the scope of this study. This study is about the self-and peer-assessment in the AAT department at Botho University. The research also investigates whether self-and peer-assessment intervention prepares the students to be responsible and accountable when they are employed in future. The next section explores the significance of this study.

\subsection{Significance of the Study}

This section focuses on the significance of this study. The need to equip our students with skills in various methodologies of assessment is critical to their effective preparation for global employability. By and large all employers are bound to use some form of assessment in measuring performance and utility of their employees to their business operations. This study will hopefully shed some light on the how we utilise current and recommended assessment methodologies in the processes of enhancing global employability of our graduates.

The subsequent section explores the literature review pertaining to this study.

\section{Literature Review}

This section reviews theoretical and empirical literature pertaining to self-assessment and peer-assessment, particularly in relation to lifelong learning. The next section explains the five stages of professional development.

\subsection{Metaphors, Five Stages of Professional Development}

This section focuses on the five stages for professional development, which helps students in the AAT department to identify their levels of entry into employment world. [3] postulates that there are five stages of professional development from novice to expert which were summarised in Table 1 below. 
Table 1. The professional practice implications of the five levels of expertise (“Adapted from Daley, 1999; 2000; 2001; McDonald, 2001”)

\begin{tabular}{|c|l|l|l|}
\hline Level of expertise & \multicolumn{1}{|c|}{ Situational awareness } & General practice application & \multicolumn{1}{|c|}{ Application } \\
\hline Novice & $\begin{array}{l}\text { Little experience with real } \\
\text { situations }\end{array}$ & $\begin{array}{c}\text { Rely on rule - oriented } \\
\text { behaviour to guide practice }\end{array}$ & $\begin{array}{l}\text { Junior clerks acquired a diploma in AAT. Draws on own } \\
\text { experiences as student for Botho University through the } \\
\text { self-and peer-assessment intervention. }\end{array}$ \\
\hline $\begin{array}{c}\text { Advanced } \\
\text { Beginner }\end{array}$ & $\begin{array}{l}\text { Able to differentiate between } \\
\text { situations }\end{array}$ & Can cope with reality & $\begin{array}{l}\text { Assistant accountant-experience in all fields of practice } \\
\text { but not considered an expert }\end{array}$ \\
\hline $\begin{array}{c}\text { Competent } \\
\text { professional }\end{array}$ & $\begin{array}{l}\text { Usually has three to five } \\
\text { years of experience in } \\
\text { specific field of practice }\end{array}$ & $\begin{array}{l}\text { Can organize and plan } \\
\text { activities and can cope with } \\
\text { unpredictable situations. }\end{array}$ & $\begin{array}{l}\text { Accountant competent in the preparation of financial } \\
\text { statements. Built up professional networks. Can supervise } \\
\text { large projects. }\end{array}$ \\
\hline $\begin{array}{c}\text { Proficient } \\
\text { professional }\end{array}$ & $\begin{array}{l}\text { Understands complex } \\
\text { practice-related situations }\end{array}$ & $\begin{array}{l}\text { Progresses to a holistic sense } \\
\text { of the work }\end{array}$ & $\begin{array}{l}\text { Finance Manager, this is an established accountant and is } \\
\text { respected in his or her field. }\end{array}$ \\
\hline Expert & $\begin{array}{l}\text { Transforms information into } \\
\text { practical knowledge, made } \\
\text { meaningful by context }\end{array}$ & $\begin{array}{l}\text { An involved performer, not } \\
\text { just a detached observer } \\
\text { guided by clinical reasoning } \\
\text { and professional judgement. }\end{array}$ & $\begin{array}{l}\text { Financial Director, this is a professional in the field of } \\
\text { accounting and is usually considered an expert of the } \\
\text { subject matter. Respected for competence and expertise by } \\
\text { colleagues, mentees, learners and others in the accounting } \\
\text { discipline. }\end{array}$ \\
\hline
\end{tabular}

The above levels assist the students in understanding the levels they go through after leaving the training institutions. As the students will learn to be self-directed through self-and peer-assessment intervention they become responsible and accountable to their work.

The next section focuses on Pedagogy and Andragogy principles.

\subsection{Pedagogy and Andragogy Principles}

The two terms are often used side-by-side when discussing education, training, and development. It is therefore vital to get them clarified at the outset through an explanation of these principles. "Andragogy" refers to the art and science of helping adults to learn, while "Pedagogy" is the art and science of teaching children. For centuries, educators had only one model-the pedagogical model. This is one that most educators have experience with, as it has dominated the education field until recently. As a result, adults have generally been taught as if they were children. The next section explains the characteristics of school children and adults.

\subsubsection{Characteristics of School Children and Adults}

The pedagogical model makes the following assumptions about school children.

- The learner is mainly dependent on the teacher, and is often submissive and carries out the teacher's directions.

- The child's experience is limited and depends on the teacher's experience and support in order to learn new knowledge.

- Learners become ready to learn what the teacher tells them they must learn if they want to pass.

- Learners have a subject-centred orientation to learning and see learning as acquiring matter content.

- Children are motivated by external motivators; for example the marks, the teacher's approval or disapproval and parental pressure.

According to the andragogical model, the following are some of the characteristics of the adult learner that were postulated by [4]:

- Adult learners are autonomous and self-directed. That is they need to be free to direct themselves. They need to be involved in the learning process and the educators serve as facilitators for them. Educators should allow participants to assume responsibility and accountability for presentation and group leadership.

- Adults have accumulated a foundation of experiences from their work, home as well as previous education. They need to connect learning to this knowledge or experience base. To help them do so educators should draw out participant's knowledge and experience relevant to the subject matter.

- Adults are relevancy-oriented. They must see a reason for learning something. Learning has to be applicable to their working environment or other responsibilities of value to them. Therefore, the educator should identify the objectives for them before the course or the intervention begins.

- Adults are practical. They tend to focus more on the lesson that is most useful to them in their field of work. They may not be interested in knowledge for its own sake, and as such instructors should explicitly tell them how the lesson or the intervention would be useful to their job.

- Adults need to be respected. Educators should acknowledge the wealth of experiences that the learners bring to the classroom, and treat them as equals in experience and knowledge and allow them to voice their opinions freely in class.

- Adults prefer to have some degree of control over their learning, and may need some degree of directness depending on their maturity level. They tend to be voluntary and believe that education will be helpful.

- Adults are people with bodies influenced by gravity. Frequent breaks must be planned, even if they are two-minute stretch breaks. During a lecture a short break after every $45-60$ minutes is useful.

- Adults have pride; therefore they need to be supported as individuals. They will not ask questions or answer 
questions if they are afraid of being ridiculed. Treat all comments with respect.

The educator should note that individual differences increase with age. Take into account differences in style, time, and pace of learning. Use auditory, visual, tactile and participatory teaching methods.

\subsubsection{What is an adult?}

According to [4], "a person become adult psychologically when they arrive at a self-concept of being responsible for own lives and of being self-directed". The implications are that:

- The educators should be extremely careful and sensitive to individual adults under their care.

- While it is the psychological definition that is most crucial, the other definitions play an important part of defining adulthood.

- The educator should synchronise learning styles with methods of facilitating learning grounded in the definition of an adult.

- The pedagogical and andragogical assumptions are complementary because there are circumstances where pedagogical assumptions suit adults and vice versa.

The following section focuses on the implications for adult learning.

\subsubsection{Implications for Adult Learning}

This section focuses on the implications for adult learning that comprises of: self-concept, experience, readiness to learn, orientation towards learning.

\section{a) Self-concept}

A climate of openness and respect is helpful in identifying what learners want and need to learn. Adults enjoy planning and carrying out their own learning exercises, and they also need to be involved in evaluating their own performance.

\section{b) Experience}

Less use is made of transmittal techniques for example lectures and more of experimental techniques such as role-play. A new discovery by learners on how to learn from experience is a key to and essential for self-actualization. Mistakes are opportunities for learning. To reject adult experience is to reject the adult.

\section{c) Readiness to Learn}

Adults need opportunities to identify the competency requirements of their occupational and social roles. Adult readiness to learn and teachable moments come to a peak at those points where a learning opportunity is co-ordinated with recognition of the need to know. Adults may also best identify their own readiness to learn and teachable moments.

\section{d) Orientation Towards Learning}

Adult learning needs to be problem-centred, and not theoretically oriented. Formal course development is less valuable than finding out what learners need to learn. Adults also need the opportunity to apply and try-out learning quickly.

These were the implications of andragogy for adult learning and the next section explores on the implications for the educator.

\subsubsection{Implications for the Educator}

This section explores on the implications for an educator, which includes: self-concept, experience, readiness to learn and orientation towards learning.

\section{a) Self-concept}

Educators recognize that learners are self-directing, and treat them accordingly. The educator is a learning reference, rather than a traditional instructor, and avoids talking down to adult learners who are experienced decision-makers and self-starters. The educator should, instead, try to meet learner needs.

\section{b) Experience}

The educator should not reject the experience of the adult learner; therefore experience is viewed as foundational to all subsequent learning.

\section{c) Readiness to Learn}

Adult learners learn when they are assisted to identify gaps in their knowledge. No questions are perceived as wrong, and all questions are opportunities for learning.

\section{d) Orientation Towards Learning}

The primary emphasis in the course is on learners learning, rather than on teachers teaching. Involvement in problems to be solved, case histories, and critical incidents generally offer greater learning opportunity for adults than talking to them in a lecture.

The literature pertaining to adult students has shown that the educator should motivate the learners to be self-directed hence the need to conduct this study as an intervention. This intervention may assist Higher education institutions in employing self-and peer-assessment as a strategy which prepares students to be responsible and accountable in their future employment circles. It is important for the researcher to understand the application of the principles of pedagogy and andragogy as they act as a vehicle in the implementation of self-and peer-assessment in the classroom.

The next section explores the research design and methodology for this study.

\section{Research Design and Methodology}

This section focuses on the research design and methodology that was used in this study to collect and analyse the data. The researcher used a survey research design to investigate the impact of self-and peer-assessment in the AAT department at Botho University in Botswana. The main purpose of this study was to determine whether self-and peer-assessment prepares the students to be 
self-directed and enhance competitiveness in the employment market. In the context where students are self-directed there will be a competitive edge in the job market.

The data for this study was collected form the three classes for AAT semester three with a population of 90 students.

The next section explores on the training that was given to the participants of this intervention.

\subsection{Training of Participants on the Intervention}

The targeted control group required training before the implementation of the self-and peer-assessment intervention. The training and implementation took place on the following days; Tuesdays, Wednesdays and Thursdays in Swaneng room number 12 in Botho University. A detailed timetable for this experiment was given to the concerned students. According to [2] whenever there is a change, the majority of the people may resist because of psychological reasons such as: fear of the unknown and a natural resistance inherently in human beings, therefore there was a need conduct a quick survey using a questionnaire, to investigate whether the students accept or reject the implementation of self-assessment and peer-assessment. The implementation process of this intervention was explained in section 3.2 of this study.

\subsection{Procedures for the Implementation of Self-assessment and Peer-assessment to three Classes at Botho University}

The researcher a teacher for AAT Basic Costing was challenged to prepare students to be accountable and responsible through self-assessment and peer-assessment. Therefore there was a need for the AAT students to write six mock assessments before final examination because this was part of their deep learning. The author of this paper was convinced that at least $85 \%$ of the students may obtain competency results if they work on all the six practice assessments. The challenge to the researcher was to train the students to self-assess and peer assess their own work in order to get prompt feedback. The only panacea to the researcher's problem was the implementation of self-assessment and peer-assessment in to his classes. The researcher used the three classes as the control group for the other AAT classes, therefore if this implementation proved to be successful; it would then be extended to other classes. Furthermore, this intervention was very important to the AAT department because if positive results would be yielded this same approach may be implemented across the AAT department. [9] pointed out that there are various benefits which accrues to a proper implementation of self-assessment and peer-assessment and some of these benefits include; students would learn from themselves and others; peer assessment may, in some ways assess the students' performance more effectively and objectively; the individual student will work very hard in order to cope with the team; the individual student contribute to the group work and is perceived as motivated; students would appreciate the role they play in setting out a criteria for standardisation; the involvement and engagement of students in devising the assessment criteria would be an effective way of developing their understanding of the criteria and contributed to their favourable attitudes towards the use of self-assessment and peer-assessment; self-assessment and peer-assessment assists students in problem solving and decision making; self-assessment and peer-assessment will enhance team building and cooperation among the teams and it will be very easy for the teachers to coordinate their classes as good spirit and cooperation will have been enhanced in the classes. Furthermore, the self-assessment and peer assessment improves the teacher and student's relationship.

The implementation of this approach would be based on the outcome from the quick survey through a questionnaire, which the researcher gave to his classes asking the students whether they support self-assessment and peer-assessment. The questionnaire was completed by the students after training on the benefits of self-assessment and peer-assessment. The researcher proceeded with the implementation after more than $50 \%$ of majority of the students accepted the self-and peer-assessment approach. A brief summary of the training to the three classes was explained in section 3.3 of this study.

\subsection{Training on the Benefits for Self-assessment and Peer-assessment}

Training of the students was vital to this intervention because the success of this experiment depended on the students' competency to carry out this task. Furthermore, training and support in the developing of the skills necessary for accurate grading appears to pay off. Training of participants yielded better results from the exercise and foster confidence to the students. Training is a systematic process of developing the knowledge, skills and attitude required by an individual to perform adequately a given task or job [7]. The students' behaviour changed after this effective training. The researcher was convinced that the students understood the importance of the self-assessment and peer-assessment hence a quick survey was conducted as explained in section 3.4 of this study.

\subsection{Administration of the Quick Survey}

The researcher gave the students a questionnaire with instructions on how to complete it and it took them approximately half an hour to complete. The students were told not to complete their names on the questionnaire. The importance of the questionnaire was explained during the training sessions and all the questionnaires were completed. The questionnaires were given to the ninety students who were in the researcher's classes.

The results from a quick survey were analysed in section 4 of this study. 


\section{Analysis of the Results from the Quick Survey}

\subsection{Outcome from the Quick Survey}

The students supported the idea of self-assessment and peer-grade; the results of the quick survey are shown on table 2 below:

Table 2. Results of the quick survey

\begin{tabular}{|c|c|c|c|c|c|c|}
\hline no. & Question & $\begin{array}{l}\text { Strongly } \\
\text { agree }\end{array}$ & Agree & Disagree & $\begin{array}{l}\text { Strongly } \\
\text { Disagree }\end{array}$ & $\begin{array}{c}\text { Total } \\
\text { Students }\end{array}$ \\
\hline 1 & Self-assessment and peer-assessment is a vehicle for formative feedback & 65 & 21 & 4 & 0 & 90 \\
\hline 2 & $\begin{array}{l}\text { Self-assessment and peer-assessment prepares students to be } \\
\text { accountable and responsible }\end{array}$ & 66 & 24 & 0 & 0 & 90 \\
\hline 3 & Self-assessment change students' behaviour and attitudes & 22 & 66 & 0 & 2 & 90 \\
\hline 4 & $\begin{array}{l}\text { Self-assessment and peer-assessment enhances students' learning and } \\
\text { stimulates motivation }\end{array}$ & 77 & 13 & 0 & 0 & 90 \\
\hline \multirow[t]{2}{*}{5} & $\begin{array}{l}\text { Self-assessment and peer-assessment foster the students' performance } \\
\text { and participation }\end{array}$ & 0 & 88 & 2 & 0 & 90 \\
\hline & Total & & & & & \\
\hline
\end{tabular}

The responses were very good where the overall percentage of the students strongly agreed and agreed that there were benefits in the self-and peer-assessment intervention. This reflected that the students understood the benefits of self-and peer-assessments. The results were also interpreted in graphs below:

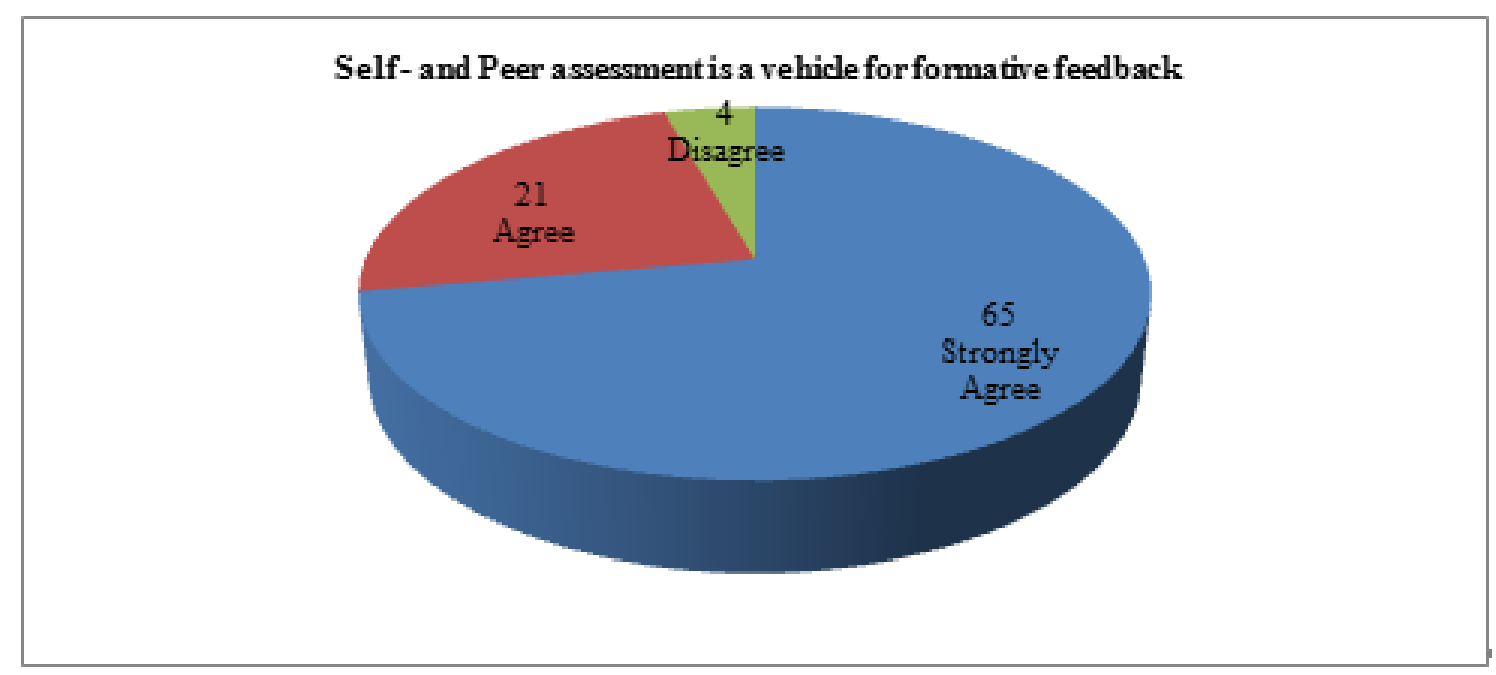

Graph 1.1. Self-assessment and peer-assessment is a vehicle for formative feedback

The results above reflect that $96 \%$ of the respondents agreed that self-and peer-assessment provides as a vehicle for prompt and formative feedback. 


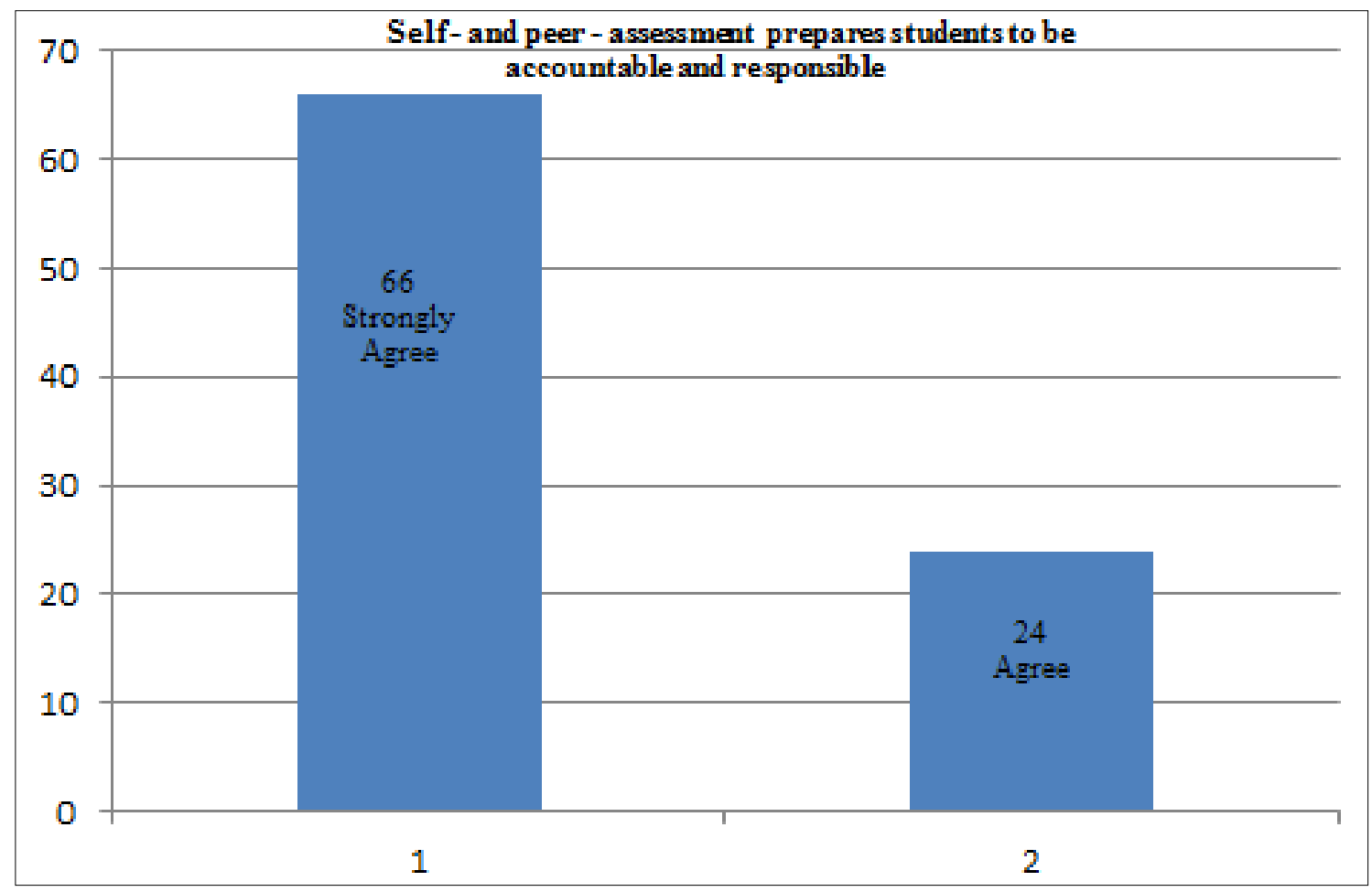

Graph 1.2. Self-assessment and peer-assessment prepares students to be accountable and responsible

The results above indicated that $100 \%$ of the respondents agreed that self-and peer-assessment prepares students to be accountable and responsible.

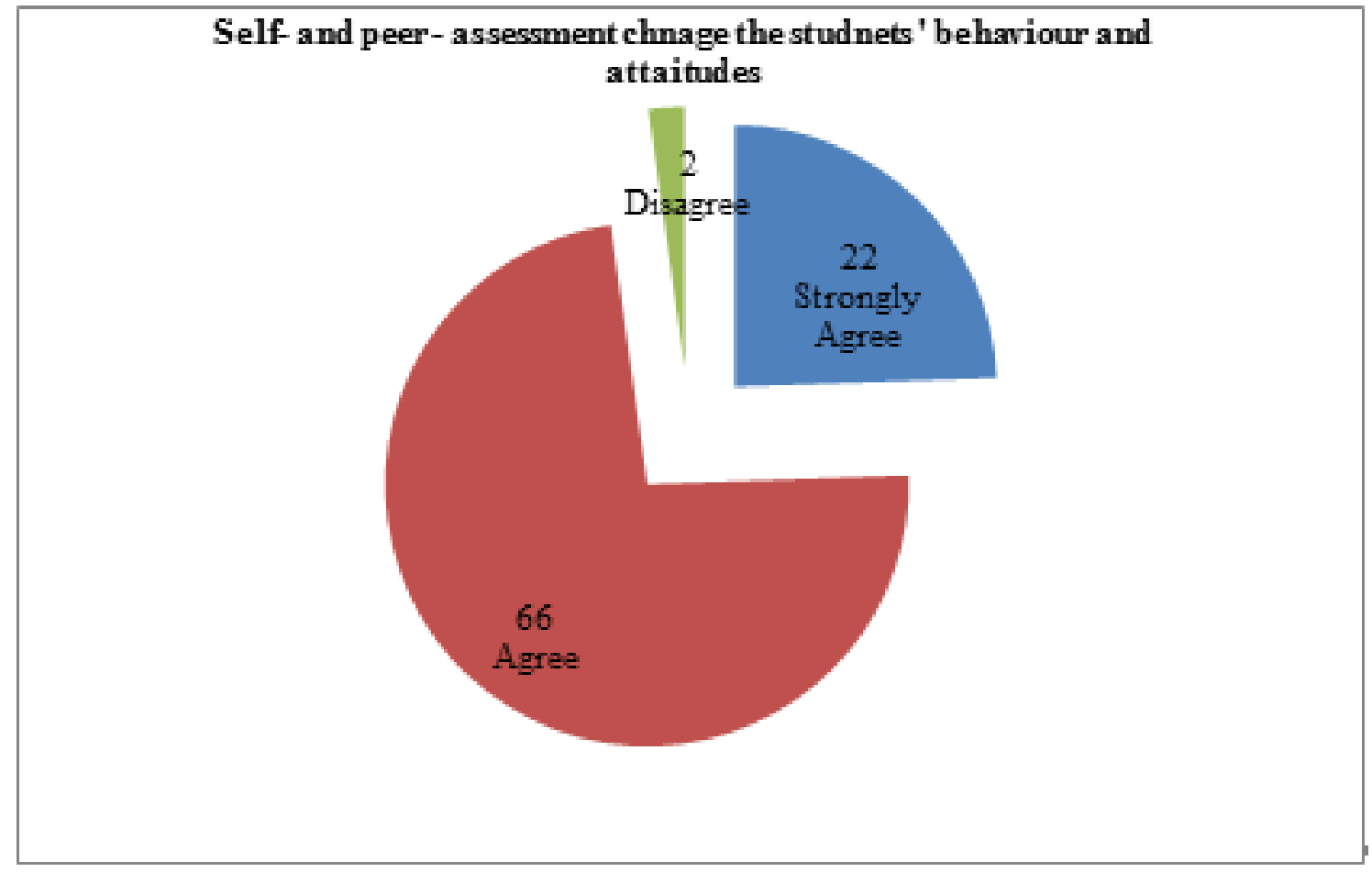

Graph 1.3. Self-assessment change students' behaviour and attitudes

The above graph reflected that $98 \%$ of the respondents agreed that self-and peer-assessment change the students' behaviour and attitudes. The $2 \%$ represented the students who were biased towards the intervention and they were students with negative attitude towards this intervention. 


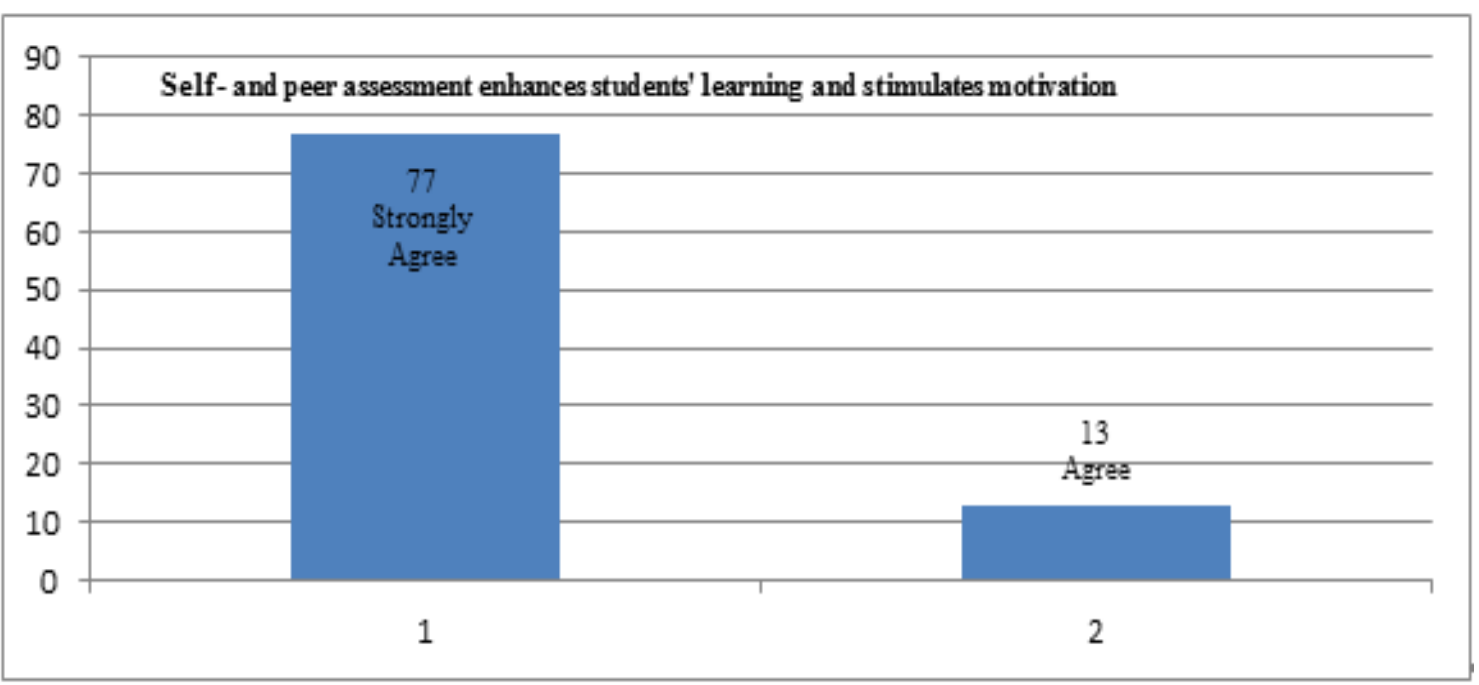

Graph 1.4. Self-assessment and peer-assessment enhances students' learning and stimulates motivation

The above graph reflects that $100 \%$ of the respondents agreed that self-and peer-assessment enhances students' learning and stimulates motivation. This study also proved that motivated students are self-directing and they cooperate by adhering to instructions and set standards. However, this concept of self-directing will assist students when they are employed as they are expected to work with minimum supervision.

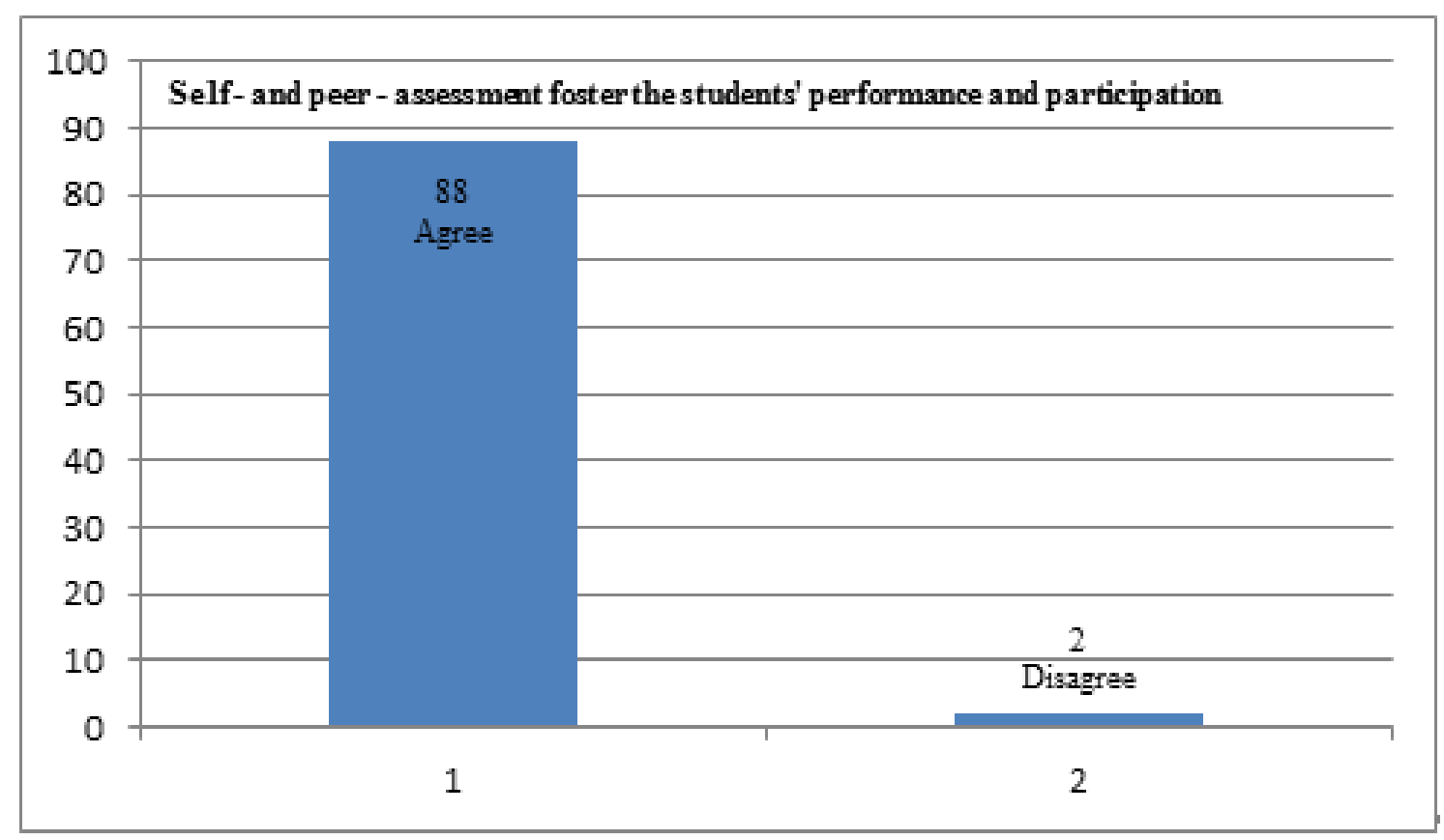

Graph 1.5. Self-assessment and peer-assessment foster the students' performance and participation 
The results above shows that $98 \%$ of the respondents agreed that self-and peer-assessment foster the students' performance and participation. Therefore it is important for students to peer-review other students' work because the rate of performance will be enhanced.

Finally the above results indicated that the majority (96\%) of the students agreed with the concept of self-assessment and peer-assessment except for a $4 \%$ of the students who disagreed to the idea. The results were very favourable and the researcher proceeded with the intervention. It was very inevitable for the researcher to plan for the intervention and this was explained in section 5 of this study.

\section{Planning for the Intervention}

The results from the quick survey were positive and shown that the researcher should proceed with the intervention. In order for the researcher to progress and succeed in this intervention it was imperative to plan how to carry out the experiment. A detailed plan was drawn out which included a workshop on how to standardize a practice assessment. The next section explains how to conduct a standardisation on AAT Basic Costing practice assessment.

\subsection{Workshop on Standardisation of Practice Assessments}

The researcher conducted a workshop on how to standardize an AAT Basic Costing practice assessment using the self-assessment and peer-assessment principles. The researcher used the first practice assessment in the AAT Basic costing as dummy assessments for both self-assessment and peer-assessment. A dummy sample of the assessment was used for standardisation. The researcher was very happy with the students' performance during the standardisation and this lead to the implementation stage on section 5.2 of the study.

\subsection{Implementation Stage}

The implementation of self-assessment and peer-assessment was launched after achieving a deviation on the standardization of marks equal to $3 \geq-3$. The researcher gave the students practice assessment 2 to write as a test. The students were given practice assessment 2 to write in class and the answer scripts were collected for self-assessment. The students marked their own work and the process took one-hour thirty minutes. The students' own grading was recorded. The teacher (researcher) marked the same papers and it took him three days to complete the assessment and recording of grades. The students and the teacher's grades were recorded in section 5.3 of this study.

\subsection{Results on Self-assessment}

The results for the students' self-assessment and the teacher's results from practice assessments 2 for AAT Basic Costing are shown on table 3 below:

Table 3. Comparisons of results for students' self-assessment and my assessments (teacher's grades with one of the classes)

\begin{tabular}{|c|c|c|c|c|}
\hline Range \% & Student-Self-Assessment & $\begin{array}{c}\text { Teacher's } \\
\text { Assessment }\end{array}$ & Variance & Outcome \\
\hline Grading & $\mathbf{( F )}$ & $\mathbf{( F )}$ & & \\
\hline $0 \leq 69$ & 2 & 3 & -1 & NYC \\
\hline $70-79$ & 12 & 13 & -1 & $\mathrm{C}$ \\
\hline $80-89$ & 9 & 9 & 0 & $\mathrm{C}$ \\
\hline $90-99$ & 7 & 5 & 2 & $\mathrm{C}$ \\
\hline 100 & 0 & 0 & 0 & $\mathrm{C}$ \\
\hline Total & 30 & 30 & & \\
\hline
\end{tabular}

Key:

Competent $=\mathrm{C}$

Not yet competent $=$ NYC

Frequency $=\mathrm{F}$ 
The results reflected a low variance between the teachers' assessment and students' self-assessment. The differences were in the range between 0 to $69 \%, 70$ to $79 \%$ and 90 to $99 \%$. The variances in the analysis above have shown a positive relationship between the teacher's marking and the students' self-assessment. The teacher's results were almost similar to the results in [8]'s paper which indicated a very small margin on the variances. Therefore, this intervention supports the idea that the students should assess their own performance.

\subsection{Results for Peer-assessment}

The students were given practice assessment six and asked to peer-review each other's work. The results for peer-assessment are shown in table 4 below.

The results above indicated that the students' peer-assessment and the teacher's marking were close to each other and there were low variances which are statistically acceptable. The variances were from the students who were biased towards high performers and awarded them with low marks. The process also experienced that the high performers also awarded high marks to low performers; this same problem was experienced in [8]. A cure to this problem was to rigorously train the students in order to reduce the level of biasness.

\section{Feedback from Students}

The majority of the students enjoyed the intervention on self-assessment and peer-assessment, except for few who were not supporting the idea. The students gave positive verbal and written feedback; and they were willing to continue with the self-assessment and peer-assessment in future.

\section{The Researcher's Feedback to Students}

The researcher organized a short briefing in order to appreciate the students' work. The researcher also appreciated their cooperation and participation which made this event a success. The researcher motivated his students to encourage other classes in accepting this idea of introducing self-assessment and peer-assessment.

\section{Summary}

This intervention has proved that there are many benefits associated with self-assessment and peer-assessment to the students, teachers and the institution at large. The intervention also fosters continuous and quality improvement in the teaching field. Therefore the researcher recommended this intervention to the AAT department.

\section{Evaluation of the Study}

This study focused on the areas that are included in the teaching, learning and assessment. The areas covered were, assessments, formative feedback and directed learning. The students were expected to learn by doing and hence this influenced directed learning. The students received prompt formative feedback and this assisted them in understanding taught concepts. The students quickly reflected on their learning and changed their ideas after seeing other students' work. The students worked on their assessments and learned from other pupils' ideas and made adjustments to their work. This is perceived as self-directed learning. The intervention encouraged students to adapt a concept of deep learning because assessing requires deep understanding of the subject matter. Lastly this study influenced the researcher to explore in future a research on whether to accept the credibility of grades on final results based on self-and peer-assessments.

\section{Recommendations}

Based on the results from the participants it was recommended that self-assessment and peer-assessment enhance learning in higher education hence the need to implement these teaching intervention strategies. This study's recommendations are limited to formative assessments. However, the researcher challenges other researchers to consider future studies for self-assessment and peer-assessment focusing on summative assessments.

Table 4. Comparisons of students' peer-assessment results and teacher's grades

\begin{tabular}{|c|c|c|c|c|}
\hline Range \% & Student-peer-Assessment & $\begin{array}{c}\text { Teacher's } \\
\text { Assessment }\end{array}$ & Variance & Outcome \\
\hline Grading & (F) & $(\mathbf{F})$ & & \\
\hline $0 \leq 69$ & 2 & 3 & -1 & NYC \\
\hline $70-79$ & 15 & 16 & -1 & C \\
\hline $80-89$ & 12 & 10 & 2 & C \\
\hline $90-99$ & 1 & 1 & 0 & C \\
\hline 100 & 0 & 30 & & 0 \\
\hline Total & 30 & & \\
\hline
\end{tabular}

Key:

Competent $=\mathrm{C}$

Not yet competent $=$ NYC

Frequency $=\mathrm{F}$ 


\section{Conclusions}

This intervention assisted AAT department at Botho University as it was implemented properly across the Faculty of Accounting and Finance. Therefore, there are many positive benefits that accrue from implementing a self-assessment and peer-assessment that includes, inter alia; self-directing, learning by doing and prepare students' employability skills as this involves collaboration and self-judgement. These interventions may only be successful through the support from the leadership in higher education.

\section{REFERENCES}

[1] Black, P., Harrison, C., Lee, C., Marshall, B. \& William, D. (2004). Working: Inside the Black Box: Assessment for Learning in the Classroom. Phi Delta Kappan.

[2] Cronje, DE. J \& Smit, P. J. (1997). Management Principles. $2^{\text {nd }}$ ed. Juta \& Co, Ltd
[3] Daley, J. B. (1999). Novice to Expert: An Exploration of how professional learn. Adult education quarterly. 49:4, Summer.

[4] Knowles, M. (1990).The Adult learner: A neglected species. Houston: Gulf.

[5] Ford Slack, P.J. (1995). The Constructivist leader. New York: Teachers College Press.

[6] McDonald, B. (2007). Self-Assessment for Understanding. The Journal of Education, Trustees of Bostom University.

[7] Meyer, M. \& Botha, E. (2004). Organisation Development and Transformation in South Africa. $2^{\text {nd }}$ ed. Lexis Nexis Butterworths Durban.

[8] Sadler, P. M. (2006). The Impact of Self-and Peer-Grading on Student Learning. Science Education Department, Harvard - Smithsonian Center for Astrophysics, Cambridge, MA

[9] Sivan, A. (2002). Implementing peer assessment to enhance teaching and learning. $13^{\text {th }}$ International Conference on College Teaching and Learning, Jacksonville, Florida, USA.

[10] Townsend, G., Winning, T., and Redwood, C. (2010). The missing link: Self-assessment and continuing professional development. Australian Dental Journal.55: 15 - 19. 